(c) American Dairy Science Association, 2006.

\title{
Sensory Evaluation of Whey and Sweet Cream Buttermilk ${ }^{1}$
}

\author{
S. Jinjarak, ${ }^{\star}$ A. Olabi, ${ }^{2,3}$ R. Jiménez-Flores, $\dagger$ I. Sodini, $\dagger$ and J. H. Walker‡ \\ *Food Science and Nutrition Department, \\ †Dairy Products Technology Center, and \\ ¥Statistics Department, California Polytechnic University, San Luis Obispo 93407
}

\begin{abstract}
The objective of this work was to characterize the sensory attributes of sweet cream buttermilk (CBM) and a nontraditional product, whey buttermilk (WBM). Whey buttermilk results from processing whey cream into butter. The products were evaluated as fresh liquid buttermilk obtained directly from the butter churn, and as reconstituted buttermilk or whey buttermilk powders. Sweet cream buttermilk and WBM were produced either at the Dairy Products Technology Center (experimental samples, $\mathrm{n}=2)$ or provided by the industry $(\mathrm{n}=$ 2 from 2 different commercial sources). Nine panelists were trained for twenty-four 1-h sessions; they then rated samples on a $15-\mathrm{cm}$ line scale in triplicate using descriptive analysis. Data obtained were analyzed using SAS statistical software. Results indicated that WBM had similar sensory characteristics as regular CBM; however, there was a marked color difference between them. Liquid buttermilk was not significantly different from reconstituted buttermilk powder on many attributes. However, WBM was significantly more yellow, more sour, and more astringent than the CBM samples, and it had more cardboard flavor than the commercially produced CBM. Liquid buttermilk was not significantly different from reconstituted buttermilk powder on many attributes. However, some buttermilk types had more cardboard aroma and flavor in their powdered form than in liquid form. Most attributes showed no significant differences across replicates, indicating consistency of rating. Principal component analysis showed that attributes were separated on the 2 principal components based on production site and processing form (fresh vs. reconstituted).
\end{abstract}

\footnotetext{
Received September 16, 2005.

Accepted January 11, 2005.

${ }^{1}$ Use of names, names of ingredients, and identification of specific models of equipment is for scientific clarity and does not constitute any endorsement of product by authors, California Polytechnic State University (San Luis Obispo), the Dairy Products Technology Center, or the American University of Beirut.

${ }^{2}$ Corresponding author: ammar.olabi@aub.edu.lb

${ }^{3}$ Current address: Nutrition and Food Science Department, Faculty of Agricultural and Food Sciences, American University of Beirut, Riad El Solh 1107 2020, Beirut, Lebanon.
}

Key words: buttermilk, whey, descriptive analysis, sensory

\section{INTRODUCTION}

Buttermilk product sales declined from 420.5 million to 248.1 million $\mathrm{kg}$ from 1980 to 2003 . The per capita sales of buttermilk also decreased from 1.9 to $0.9 \mathrm{~kg}$ from 1980 to 2003 (Dairy Facts, 2004). As a result, byproducts such as buttermilk have been disposed, and loss of solids and increase of waste disposal were unavoidable as predicted by Srivastava et al. (1985).

The composition of buttermilk powder is similar to skim milk powder; however, buttermilk contains more fat and more milk fat globule membrane (MFGM) components (Malin et al., 1994). The MFGM is abundant in phospholipids, including phosphatidylcholine (lecithin), phosphatidylethanolamine, and sphingomyelin. The MFGM phospholipids, especially sphingomyelin, are known to have beneficial health effects (Corredig and Dalgleish, 1997), which may help prevent the onset of cancer and control the growth of cancerous cells (Parodi, 1999). Under industrial processing, sphingomyelin was more retained in the MFGM than were other phospholipids (Bitman and Wood, 1990).

Having a high phospholipids content, buttermilk is used as a functional ingredient in many food products such as salad dressings, pasta sauces, chocolate, cheese seasonings, ice cream mixes, and yogurt (O'Connell and Fox, 2000). The main functional property of buttermilk is emulsification (Corredig and Dalgliesh, 1997; Raval and Mistry, 1999) because the MFGM helps prevent fat globules from colliding and forming lumps (Roesch et al., 2004). The functional properties of buttermilk vs. nonfat dry milk and other ingredients were assessed in several studies (Wong and Kitts, 2003a,b).

Sensory work on sweet buttermilk is limited to the use of buttermilk as an ingredient in food products to improve sensory and physical properties. This included adding it to fruit juice as a supplement (Shukla et al., 2004), to ice cream as a substitute for nonfat dry milk (Hanumantha Rao and Atmaram, 1986; Tirumalesha and Jayaprakasha, 1988), and to yogurt (Mansour et al., 1994; Trachoo and Mistry, 1998) to improve texture. In addition, buttermilk was to added to chocolate (Liang 
and Hartel, 2004), reduced-fat Mozzarella cheese (Poduval and Mistry, 1999), and Cheddar cheese (Mistry et al., 1996). Buttermilk was also used in cheese spreads (Gokhale et al., 1999), and reduced-fat processed cheese (Raval and Mistry, 1999). Muir et al. (1999), using sensory evaluation, noted similarities in the sensory properties of traditional Polish kefir and buttermilk, because both were acidic with some bitter notes.

Another source for MFGM components is whey cream produced from cheese whey. Whey is typically drained after the cheese curd is formed, and in the past discarded as a waste product or further processed for use as animal feed (Maubois et al., 1987). Whey is mostly used as a powder after being processed by spray drying. Whey powder has functional properties (Hall and Iglesias, 1997) and nutritional components with biological value, such as $\alpha$-LA, $\beta$-LG, and lactoferrin, that help reduce health risks (Smithers et al., 1996). Today, whey is a valuable ingredient and large volumes are processed for the production of whey protein-rich ingredients. Essential to their processing is the removal of residual fat.

Moreover, whey proteins have been used as ingredients in infant formulas, sport bars, bakery products, and yogurt. Whey protein films and coatings were used for chocolate and cheese coating (Balagtas et al., 2003). Whey and whey buttermilk have been incorporated into fruit drinks, which were favorably received by consumers (Farah and Bachman, 1981; Srivastava et al., 1985; Shukla et al., 2004).

High heat treatment is known to reduce oxidation rate and control defects such as metallic and oxidized off-flavors in buttermilk. Metallic off-flavor usually has an astringent component. Phospholipids containing unsaturated fatty acids are prone to oxidation and hence to an oxidized flavor defect (Bodyfelt et al., 1988). Drake et al. (2003) stated that processing and composition have influence on flavor. Milk powder that was either fresh or stored was reconstituted and had attributes such as cooked, oxidized, and acidic (Drake et al., 2003).

Fresh and stored skim milk powder had different aroma and flavor profiles showing the significant impact of processing, raw materials, and storage on the sensory profiles of skim milk (Karagül-Yüceer et al., 2004). Drake et al. (2003) examined the flavor profile of several dairy powders such as skim milk powder, whole milk powder, whey protein isolates, and whey protein concentrates, and found similar attributes to those reported by Karagül-Yüceer et al. (2004); for example, cooked, sweet, and astringent flavors in addition to cardboard flavor in skim milk powder. Thus, the initial composition of milk can be associated with the sensory properties of products. Hough et al. (2002) sug- gested that off-flavors in milk powder are the main factor affecting low acceptability by consumers.

Spill (2002) assessed the sensory attributes of reconstituted sweet cream buttermilk and the influence of varying processing and temperature conditions on these attributes. Samples used were reconstituted sweet cream buttermilks. In addition, a sensory lexicon was developed (Spill, 2002). The author found that high heat storage and storage time were associated with attributes such as oxidized, cardboard, and astringent flavors. Samples kept at high temperature for $14 \mathrm{~d}$ began to produce off-flavors. The presence of MFGM components in buttermilk and their associated health effects is a promising factor in terms of achieving a better valorization of buttermilk. The increase in cheese production and consequently whey production (Balagtas et al., 2003) requires more efficient use of the different whey components. The objectives of this work were first, to characterize the sensory attributes of reconstituted and fresh liquid sweet cream and whey buttermilks, and second, to assess the effect of treatment and physical form on the sensory attributes of experimental and commercial samples. This work is an exploratory study with the goal of comparing different types of buttermilks (sweet cream and whey) and not with the goal of assessing the effect of different processing parameters on the sensory quality of products. Thus, samples from different sources/processing conditions were selected.

\section{MATERIALS AND METHODS}

\section{Treatments}

Formulations. Samples consisted of 2 sweet cream commercial buttermilks and 2 experimental buttermilks (sweet cream and whey). Commercial samples were provided by dairy companies in California from 2 production dates. The experimental buttermilks were produced at the Dairy Products Technology Center at California Polytechnic State University (San Luis Obispo) and included a sweet cream buttermilk (CBM) and whey buttermilk (WBM). The experimental samples were produced in 2 batches. All buttermilks were produced in 2 forms: spray-dried powder and liquid. Accordingly, the total number of samples was 16 (4 treatments $\times 2$ forms $\times 2$ batches). The experimental design is illustrated in Figure 1.

Processing. Sweet cream and whey cream were provided by Foster Farms (Modesto, CA) and Hilmar Cheese Company (Hilmar, CA). They were churned after a waiting period of $16 \mathrm{~h}$ at $4^{\circ} \mathrm{C}$. Sweet cream was churned to butter using a continuous pilot-scale butter churn (Egli AG, Bütschwil, Switzerland). Buttermilk was drained into a milk vat after butter fines were removed by filtration through cheesecloth, and spray- 


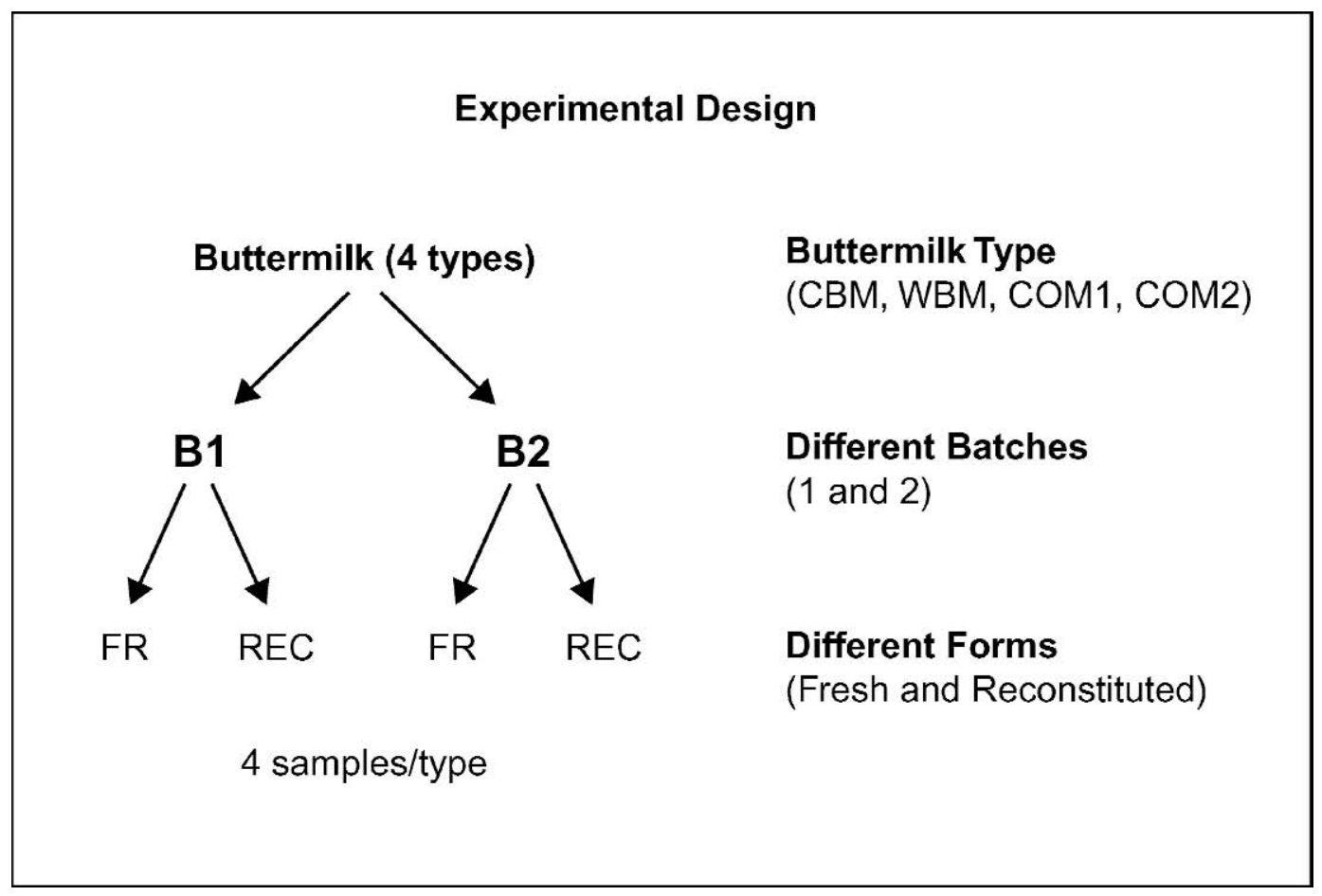

Figure 1. Experimental design of study. Types: experimental sweet cream buttermilk (CBM), experimental whey buttermilk (WBM), and 2 commercial sweet cream buttermilks (COM1 and COM2).

dried using a Niro Filterlab Spray Drier (Hudson, WI) at an intake air temperature of $221^{\circ} \mathrm{C}$ and at an exhaust air temperature of $82.2-85.0^{\circ} \mathrm{C}$. Buttermilk powder was stored in a ventilated room at $10^{\circ} \mathrm{C}$. Liquid buttermilk from the churn was frozen fresh with liquid nitrogen, then immediately stored in a freezer at $-34^{\circ} \mathrm{C}$ before sensory evaluation. The buttermilk was produced through normal butter processing in 2 batches at the Dairy Products Technology Center using 2 different batches of the 2 creams.

Storage. Buttermilk powders were stored in plastic bags within closed cardboard boxes, and stored in a ventilated room at $10^{\circ} \mathrm{C}$ before sensory evaluation. Fresh liquid buttermilk was transferred to $100-\mathrm{mL}$ plastic vials, frozen in liquid nitrogen, and kept in closed cardboard boxes in the freezer at $-34^{\circ} \mathrm{C}$. The vials were removed to $5^{\circ} \mathrm{C}$ refrigerator to thaw $2 \mathrm{~d}$ before evaluation.

\section{Chemical Analyses}

Total nitrogen content, nonprotein nitrogen, fat, moisture, ash, lactose and $\mathrm{pH}$ level were determined as well as solubility, viscosity, emulsifying power, and foaming capacity, as described in a study by Sodini et al. (2006).

\section{Descriptive Analysis}

Training. Nine panelists ( 6 females, 3 males, ages 21 to 37), who were students, staff, and faculty at California Polytechnic State University, were trained over twenty-four 1-h sessions, twice per week, for $12 \mathrm{wk}$. The training included both commercial and experimental (produced at the Dairy Products Technology Center) samples in powder (liquid reconstituted from powder) and liquid (thawed from frozen) forms. The training included tasting different buttermilk samples and discussing their characteristics. The panelists generated 17 attributes and definitions in the training sessions, along with reference standards for several of the attributes (Table 1).

Evaluation. During the evaluation period, the panelists attended 12 sessions (1 morning and 1 afternoon session each day) for $3 \mathrm{~d}$ per week over 2 wk. Four samples were served at each session. The order of the samples was randomized for the panelists over every 2 -d period, which corresponded to a replicate. There were 3 replicate evaluations ( 1 per 2 -d period) with all 16 samples ( 4 treatments $\times 2$ forms $\times 2$ batches) served within each replicate. Samples reconstituted from powder were freshly mixed each day 1 to $2 \mathrm{~h}$ before serving based on a 9:1 ratio of water to powder and then adjusted to $10^{\circ}$ Brix as described in Spill (2002). Samples 
Table 1. List of attributes and reference standards for descriptive analysis of sweet cream and whey buttermilk samples

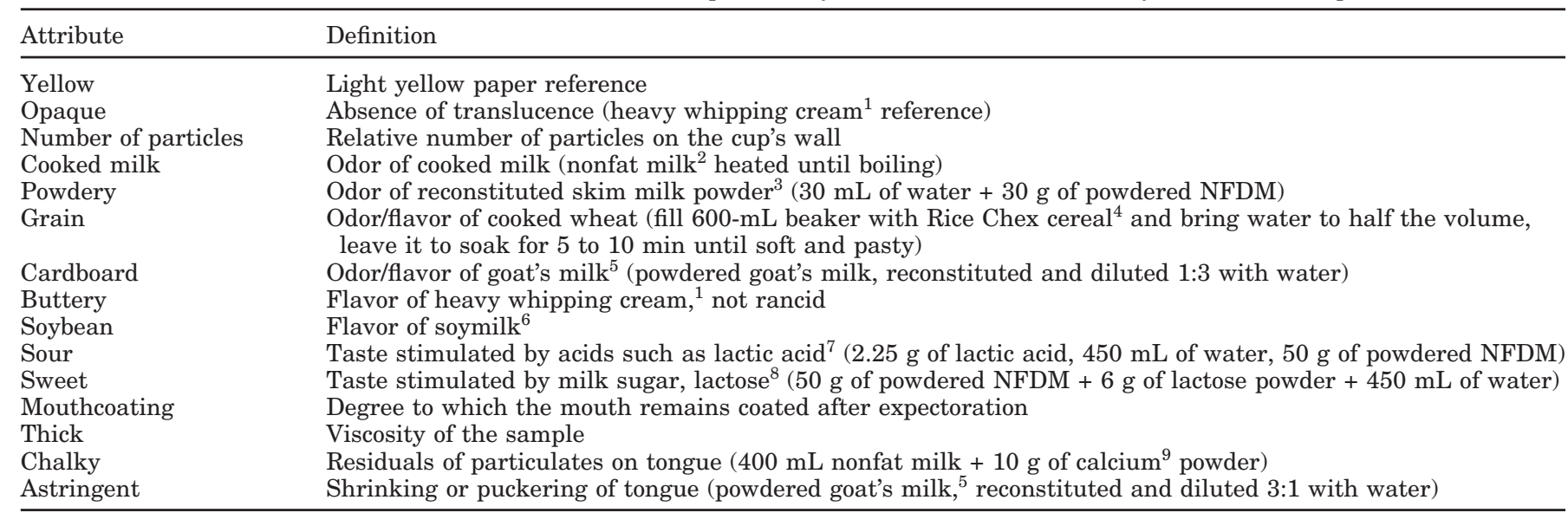

${ }^{1}$ Alta Dena, City of Industry, CA.

${ }^{2}$ First Street Dairy, City of Industry, CA.

${ }^{3}$ Nestle's Carnation, Chatsworth, CA.

${ }^{4}$ General Mills Rice Chex, Minneapolis, MN.

${ }^{5}$ Meyenberg, Turlock, CA.

${ }^{6}$ Vitasoy, Ayer, MA.

${ }^{7}$ Purac, Lincolnshire, IL.

${ }^{8}$ Proliant, Ankeny, IA.

${ }^{9}$ Kelatron Corp, Ogden, UT.

were first prepared and then kept in a $5^{\circ} \mathrm{C}$ refrigerator until 30 min before serving when samples were placed at room temperature to temper. Cups were covered with plastic lids to preserve the odor of samples. Samples $(50 \mathrm{~mL})$ were given to panelists monadically in 148$\mathrm{mL}$ plastic cups (Tumblers, Waddington North America Inc., City of Industry, CA), labeled with 3-digit numbers. Standard references were given to panelists. Panelists were instructed to rinse their mouths with spring water before evaluating each sample and to expectorate all water and buttermilk afterwards. Spoons were given to panelists for stirring the samples before evaluation. Attributes were rated on a 15 -cm line scale score sheets. Judges were compensated with gift certificates to local stores of their choice.

\section{Statistical Analysis}

Data related to sensory analyses were analyzed using the Proc Mixed procedure of SAS (version 8.02, 19992001; SAS Institute Inc., Cary, NC). An ANOVA was performed to evaluate the effects of panelist, type (4 types: 2 commercial CBM, experimental CBM, and experimental WBM), form (powder vs. liquid), replicate, and their interactions. Significant means for the sensory analyses were separated by Tukey's honestly significant difference (HSD) test. Significance was preestablished at $\alpha<0.05$. It is important to note that, from a statistical standpoint, the results in Table 2 include tests of 17 different sensory attributes for 6 different main effects and interactions. With a $5 \%$ significance level attached to each test, the chance of incorrectly finding a significant difference in at least one of these tests is extremely high. Accordingly, it is safest to assume that only the tests with a $P$-value $<0.001$ show a real difference and that tests with $P$-values between 0.001 and 0.05 should be interpreted with caution. In addition, principal components analysis was performed using the 24 means from the 8 different buttermilk samples for each of the 3 replications using SAS (version 8.02, 1999-2001)

\section{RESULTS AND DISCUSSION}

\section{Descriptive Analysis}

ANOVA and HSD. The results of the ANOVA for sensory data, including the $F$-values and probability levels for the different attributes, are summarized in Table 2. Least squares means are summarized in Tables 3 and 4 . Table 3 shows the least squares means of all 17 sensory attributes for each of the 4 buttermilk treatments (experimental WBM, experimental CBM, and 2 commercial CBM) and for both buttermilk forms (fresh liquid and reconstituted from powder). Table 4 displays only those sensory attributes with significant $(P<0.05)$ treatment $\times$ form interactions. For these attri- 
Table 2. Significance ( $F$-values) of effects of treatment, form, replicate, and interactions on the sensory properties of buttermilk samples ${ }^{1}$

\begin{tabular}{lccllcl}
\hline \multicolumn{7}{c}{ Effect } \\
\cline { 2 - 7 } Attribute & $\begin{array}{l}\text { Treatment }(\mathrm{T}) \\
\mathrm{df=3}\end{array}$ & $\begin{array}{l}\text { Form }(\mathrm{F}) \\
\mathrm{df}=1\end{array}$ & $\begin{array}{l}\text { Replicate }(\mathrm{R}) \\
\mathrm{df=2}\end{array}$ & $\begin{array}{l}\mathrm{T} \times \mathrm{R} \\
\mathrm{df}=6\end{array}$ & $\begin{array}{l}\mathrm{T} \times \mathrm{F} \\
\mathrm{df}=3\end{array}$ & $\begin{array}{l}\mathrm{F} \times \mathrm{R} \\
\mathrm{df}=2\end{array}$ \\
\hline Yellow & $50.61^{* * *}$ & $7.06^{*}$ & 0.92 & 0.62 & 1.36 & $4.92^{* *}$ \\
Opaque & 2.84 & $10.69^{*}$ & 1.08 & 0.78 & $3.10^{*}$ & 0.46 \\
Number of particles & $7.70^{* *}$ & $10.50^{* *}$ & 0.30 & 1.29 & 2.35 & $4.60^{*}$ \\
Cardboard odor & $7.25^{* *}$ & $35.49^{* * *}$ & $4.40^{*}$ & 1.12 & $20.07^{* * *}$ & 2.17 \\
Grain odor & $5.47^{* *}$ & 0.52 & 1.26 & 0.63 & 1.60 & 1.85 \\
Cooked milk odor & 1.11 & 0.88 & 1.09 & 0.86 & 2.14 & 3.56 \\
Powdery odor & 2.06 & $8.26^{*}$ & 1.82 & 1.54 & 1.61 & 0.55 \\
Cardboard flavor & $12.18^{* *}$ & $32.14^{* * *}$ & 0.28 & 0.49 & $10.53^{*}$ & 1.82 \\
Sweet flavor & 2.27 & 1.27 & 0.30 & 0.64 & 1.53 & 0.75 \\
Buttery flavor & 1.29 & 2.21 & 1.93 & 0.35 & 1.33 & 0.14 \\
Grain flavor & 2.80 & 0.01 & 1.75 & 0.65 & 1.06 & 1.06 \\
Sour flavor & $21.14^{* * *}$ & 0.00 & 2.38 & 0.53 & 2.42 & 1.51 \\
Soybean flavor & 0.74 & 0.45 & $4.35^{*}$ & 2.10 & 0.61 & 0.04 \\
Thick & 0.75 & 0.20 & 0.30 & 0.49 & $11.07^{* * *}$ & 2.91 \\
Chalky & 2.38 & 2.32 & 0.58 & 1.38 & 2.80 & 1.18 \\
Astringent & $15.34^{* * *}$ & 5.31 & 0.58 & 1.38 & 1.61 & 1.38 \\
Mouthcoating & 0.62 & 0.08 & 0.79 & 0.95 & 0.47 & 1.31 \\
\hline
\end{tabular}

${ }^{1}$ Treatments: experimental sweet cream buttermilk, experimental whey buttermilk, and 2 commercial sweet cream buttermilks; form $=$ reconstituted vs. fresh liquid buttermilk.

$* P<0.05 ; * * P<0.01 ; * * * P<0.001$.

butes, the means are shown for all 8 combinations of treatment and form. In cases where the treatment $x$ form interaction is significant, Table 4 displays the more complex relationship between the samples.

The ANOVA revealed significant differences between the types of buttermilk on yellow, sour, and astringent flavors $(P<0.001)$, number of particles, cardboard odor and flavor, and grainy odor $(P<0.01)$. The experimental
WBM was more yellow than the other buttermilks (CBM, COM1, and COM2; COM1 and COM2 represent 2 commercial sweet cream buttermilks), which were made from sweet cream. The higher yellowness score for WBM is because of the color of whey cream affected by the addition of annatto from cheese making. The WBM was also significantly more sour and astringent than the other 3 treatments. A lower $\mathrm{pH}$ was obtained

Table 3. Least squares mean scores of descriptive analysis attributes of treatment and form for buttermilk samples ${ }^{1}$

\begin{tabular}{|c|c|c|c|c|c|c|}
\hline \multirow[b]{2}{*}{ Attribute } & \multicolumn{4}{|c|}{ Treatment } & \multicolumn{2}{|c|}{ Form } \\
\hline & CBM & WBM & COM1 & COM2 & Fresh & Powder \\
\hline Yellow & $2.65^{\mathrm{b}}$ & $12.15^{\mathrm{a}}$ & $4.87^{\mathrm{b}}$ & $4.93^{\mathrm{b}}$ & $6.59^{\mathrm{a}}$ & $5.71^{\mathrm{b}}$ \\
\hline Opaque & 8.43 & 7.17 & 6.63 & 6.06 & $6.63^{\mathrm{b}}$ & $7.51^{\mathrm{a}}$ \\
\hline Number of particles & $7.87^{\mathrm{a}}$ & $8.41^{\mathrm{a}}$ & $4.43^{\mathrm{ab}}$ & $2.51^{\mathrm{b}}$ & $7.71^{\mathrm{a}}$ & $3.90^{\mathrm{b}}$ \\
\hline Cardboard odor & $6.82^{\mathrm{a}}$ & $5.69^{\mathrm{ab}}$ & $3.81^{\mathrm{b}}$ & $3.50^{\mathrm{b}}$ & $3.73^{\mathrm{b}}$ & $6.18^{\mathrm{a}}$ \\
\hline Grain odor & $2.18^{\mathrm{b}}$ & $2.68^{\mathrm{ab}}$ & $3.25^{\mathrm{a}}$ & $3.32^{\mathrm{a}}$ & 2.78 & 2.93 \\
\hline Cooked milk odor & 4.19 & 4.17 & 4.94 & 5.13 & 4.46 & 4.76 \\
\hline Powdery odor & 4.38 & 3.54 & 4.61 & 3.41 & $3.28^{\mathrm{b}}$ & $4.69^{\mathrm{ab}}$ \\
\hline Cardboard flavor & $6.73^{\mathrm{a}}$ & $6.71^{\mathrm{a}}$ & $4.09^{b}$ & $4.20^{\mathrm{b}}$ & $3.58^{\mathrm{b}}$ & $7.28^{\mathrm{a}}$ \\
\hline Sweet flavor & 5.87 & 4.38 & 5.77 & 5.65 & 5.00 & 5.84 \\
\hline Buttery flavor & 5.26 & 5.12 & 5.85 & 6.10 & 6.19 & 4.98 \\
\hline Grain flavor & 2.43 & 3.19 & 2.98 & 3.44 & 3.02 & 3.00 \\
\hline Sour flavor & $2.87^{\mathrm{b}}$ & $6.86^{\mathrm{a}}$ & $2.55^{\mathrm{b}}$ & $2.49^{\mathrm{b}}$ & 3.68 & 3.70 \\
\hline Soybean flavor & 2.14 & 2.66 & 2.22 & 2.55 & 2.51 & 2.27 \\
\hline Thick & 4.88 & 4.95 & 4.38 & 4.33 & 4.57 & 4.70 \\
\hline Chalky & 3.82 & 3.35 & 2.36 & 2.28 & 3.25 & 2.65 \\
\hline Astringent & $3.98^{\mathrm{b}}$ & $6.00^{\mathrm{a}}$ & $3.46^{\mathrm{b}}$ & $3.54^{\mathrm{b}}$ & 3.95 & 4.54 \\
\hline Mouthcoating & 5.02 & 5.00 & 4.35 & 4.79 & 4.73 & 4.85 \\
\hline
\end{tabular}

${ }^{a, b}$ Means with different letters are significantly different $(P<0.05)$.

${ }^{1}$ Treatments: experimental sweet cream buttermilk (CBM), experimental whey buttermilk (WBM), and 2 commercial sweet cream buttermilks (COM1 and COM2); form = fresh vs. reconstituted liquid buttermilk. 
Table 4. Least squares means of descriptive analysis attributes with significant treatment $\times$ form interaction for the 8 combinations of treatment and form ${ }^{1}$

\begin{tabular}{|c|c|c|c|c|c|c|c|c|}
\hline & \multicolumn{2}{|c|}{ CBM } & \multicolumn{2}{|c|}{ WBM } & \multicolumn{2}{|c|}{ COM1 } & \multicolumn{2}{|c|}{ COM2 } \\
\hline & Fresh & Powder & Fresh & Powder & Fresh & Powder & Fresh & Powder \\
\hline Opacity & $8.44^{\mathrm{a}}$ & $8.41^{\mathrm{ab}}$ & $6.29^{\mathrm{ab}}$ & $8.05^{\mathrm{ab}}$ & $6.16^{\mathrm{ab}}$ & $7.09^{\mathrm{ab}}$ & $5.64^{\mathrm{b}}$ & $6.49^{\mathrm{ab}}$ \\
\hline Cardboard odor & $6.13^{\mathrm{b}}$ & $7.52^{\mathrm{a}}$ & $2.79^{\mathrm{cd}}$ & $8.59^{\mathrm{a}}$ & $2.95^{\mathrm{d}}$ & $4.66^{\mathrm{bc}}$ & $3.07^{\mathrm{cd}}$ & $3.93^{\mathrm{cd}}$ \\
\hline Cardboard flavor & $6.01^{\mathrm{ab}}$ & $7.44^{\mathrm{ab}}$ & $3.85^{\mathrm{b}}$ & $9.58^{\mathrm{a}}$ & $1.95^{\mathrm{b}}$ & $6.23^{\mathrm{ab}}$ & $2.53^{\mathrm{b}}$ & $5.87^{\mathrm{ab}}$ \\
\hline Thickness & $4.74^{\mathrm{ab}}$ & $5.02^{\mathrm{ab}}$ & $4.06^{\mathrm{b}}$ & $5.84^{\mathrm{a}}$ & $4.74^{\mathrm{ab}}$ & $4.02^{\mathrm{b}}$ & $4.74^{\mathrm{ab}}$ & $3.92^{\mathrm{b}}$ \\
\hline
\end{tabular}

for the WBM compared with CBM in chemical analyses (pH 6.0 and 6.5, respectively). Remnants of lactic acid from cheese making could have affected the higher intensity for sourness and astringency in WBM, which would probably limit its use in food applications for low-acid products. Moreover, astringency was known to be the consequence of lipid oxidation and associated with pentanal and 2-4 decadienal (Carunchia Whetstine et al., 2003). Freshness and processing temperature of cream affected sensory quality of buttermilk powder; however, the latter was more critical especially in flavor (Spill, 2002).

The powdered forms of the experimental buttermilks (CBM and WBM) had a significantly stronger cardboard odor than all other samples. Fresh CBM had significantly more cardboard odor than the other 3 fresh buttermilks. In addition, powdered WBM had significantly more cardboard flavor than fresh WBM, fresh COM1, and fresh COM2, but was not significantly different from other samples. Cardboard odor and flavor are usually associated with oxidation and have been attributed to several compounds: vinylamyl ketone and aldehydes (Hammond, 1972). Off-flavors, such as cardboard, were determined to be concentration-dependent. Carunchia Whetstine et al. (2003) and Lee and Morr (1994) concluded that unsaturated free fatty acids, which are prone to oxidation, were another source for cardboard flavor in liquid whey. Milk source and different starter cultures used in cheese making also influenced compounds produced in whey and affected whey flavor (Meyers et al., 1996).

Sweet cream buttermilk and WBM had significantly more particles than COM2, and had some larger particles than COM1, but the differences were not significant. This is probably due to a more thorough processing in the industry, especially with respect to homogenization, which helps reduce the particle size and number for the commercial buttermilks. Whey buttermilk had the lowest particle size distribution and average particle size of fat globules in an emulsion (Sodini et al., 2006), which implies that the differences observed sen- sorially in this work were not related to fat globule size. Our results showed no significant interaction between treatment and form based on number of particles, indicating that the 4 treatments did not show different trends for that attribute based on their physical form (reconstituted or fresh). Particle size was determined to relate to sensory properties such as smoothness (Liang and Hartel, 2004).

Both commercial CBM samples (COM1 and COM2) had significantly higher grainy odor than the experimental CBM, but not significantly more grainy odor than the experimental WBM. Fresh CBM was significantly more opaque than fresh COM2, but no other differences in opacity were detected among the 8 samples. Powdered WBM was significantly thicker than powdered COM1, powdered COM2, and fresh WBM.

The physical form (reconstituted from powder or thawed liquid) had a significant effect on cardboard odor and flavor $(P<0.001)$, number of particles $(P<$ $0.01)$, yellow, opacity and powdery odor $(P<0.05)$. The thawed liquid samples were significantly more yellow and had significantly more particles than the powdered samples, but the fresh samples had less powdery odor. The fresh form tended to have less cardboard odor and flavor than the powdered form, but this was not uniformly significant across all 4 types of buttermilk. Powdered forms had significantly more cardboard odor for CBM, WBM, and COM1 compared with COM2. Powdered WBM had significantly more cardboard flavor than fresh WBM, but the difference was not significant for the other 3 buttermilks. No other significant differences were obtained between the 2 forms (powder or liquid).

The differences between the liquid and reconstituted forms on cardboard flavor and odor are interesting and could indicate the significant impact of processing on these attributes. Cardboard odor and flavor differences could result from the high spray-drying temperature. Spill (2002) obtained an increase in cardboard flavor and aroma in samples stored at $50^{\circ} \mathrm{C}$ for $2 \mathrm{wk}$ compared with fresh samples. Spill (2002) stated that storage 


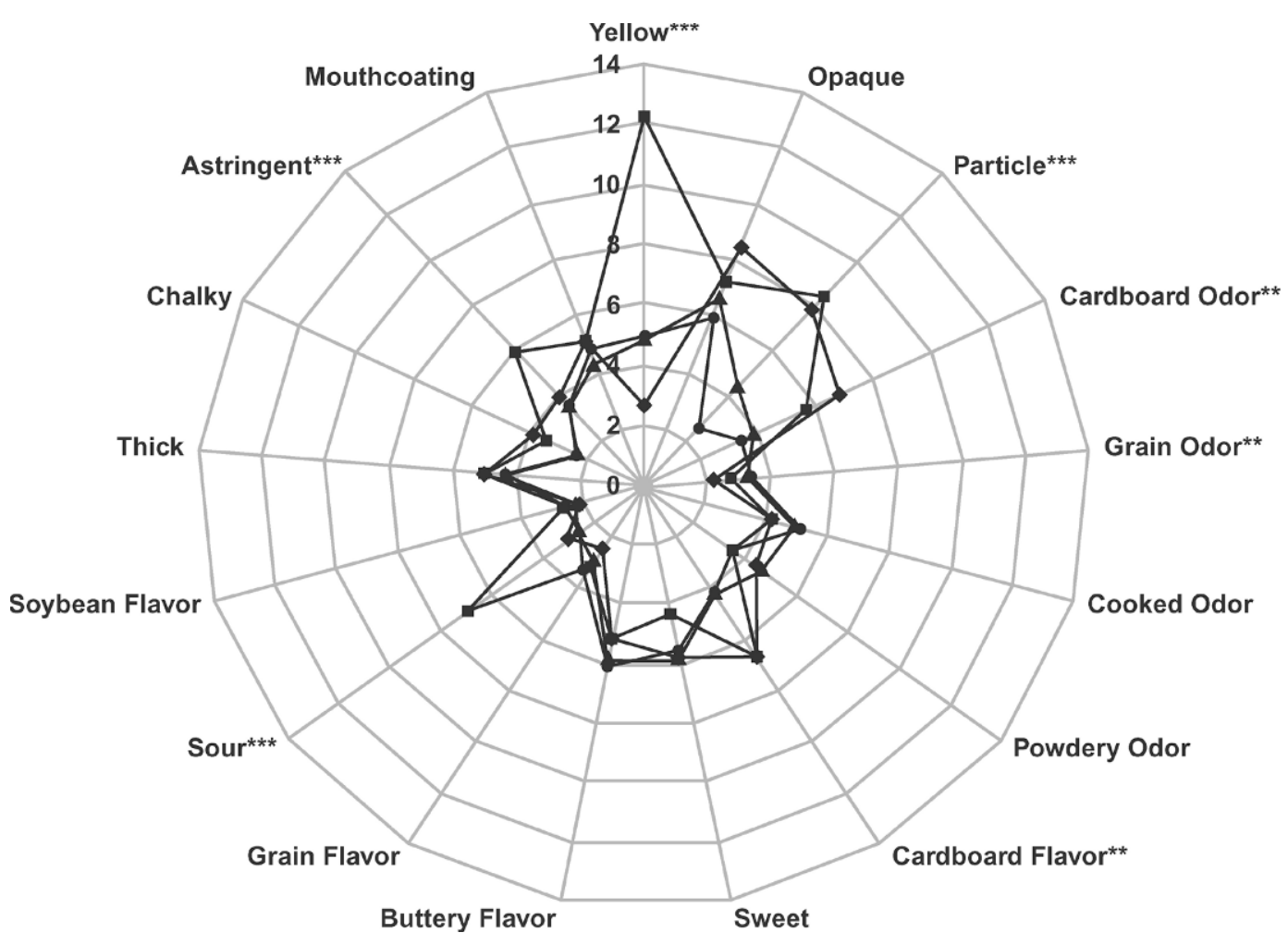

Figure 2. Spider plot of descriptive analysis attributes for buttermilk samples (experimental sweet cream buttermilk (CBM, $\bullet)$, experimental whey buttermilk (WBM, $\mathbf{\square}$ ), and 2 commercial sweet cream buttermilks (COM1, $\boldsymbol{\bullet}$, and COM2, $\mathbf{\Delta}$ ). $* P<0.05 ; * * P<0.01 ; * * * P<0.001$.

time was related to oxidation and increased cardboard aroma, cardboard flavor, and astringency, although oxidized flavor increased by a small amount for the highheat-processed samples. Nevertheless, buttermilk powder was stated to have good stability even at high storage temperatures (Spill, 2002). It is important to note that all the samples in the above-mentioned study were reconstituted from powder, and oxidized and cardboard odor were 2 distinct attributes.

No significant replicate effect was found with the exception of cardboard odor and soybean flavor $(P<$ 0.05). In addition, most of the attributes did not show significant replicate $\times$ treatment or replicate $\times$ form interactions. Exceptions were for cardboard odor and thickness $(P<0.001$ for replicate $\times$ treatment $)$ and for yellow and number of particles $(P<0.01$ and $P<0.05$ for replicate $\times$ form, respectively). The absence of major replicate, replicate $\times$ treatment, and replicate $\times$ form effects demonstrates a high level of consistency in the ratings. The least squares means of the different attributes for the different types of buttermilks are also illustrated in a spider plot (Figure 2).

Principal Component Analysis. The data were analyzed after averaging across the 9 panelists and 2 batches leaving 3 replicate observations for each of the
8 buttermilk samples (24 observations in total). The 3 replicate observations per sample were averaged to produce the positions of the 8 buttermilk samples in Figure 3 for the first 2 principal components. The first 3 principal components (PC) explained $68.3 \%$ of the variance, as illustrated by the scree plot (Figure 4). The first PC (displayed horizontally on Figure 3) separated attributes based on site of production differences (experimental vs. commercial). The negative side of PC1 included higher values of what are traditionally considered desirable attributes in buttermilk powders, such as grainy odor, cooked odor, sweetness, and buttery, whereas the positive values of PC1 were associated with higher values of more negative attributes such as cardboard odor and flavor, astringency, chalkiness, and sour flavor. The second PC (displayed vertically on Figure 3) separated the samples mostly based on form, especially for the commercial samples.

The lower right quadrant included samples 1 and 2 , which were the experimental liquid and powder CBM, with higher values of attributes such as cardboard flavor and aroma, opacity, and powdery, and lower values of buttery flavor and grainy flavor. Samples 3 and 4 (liquid and powder WBM) were associated with higher values of chalkiness, number of particles, astringent 


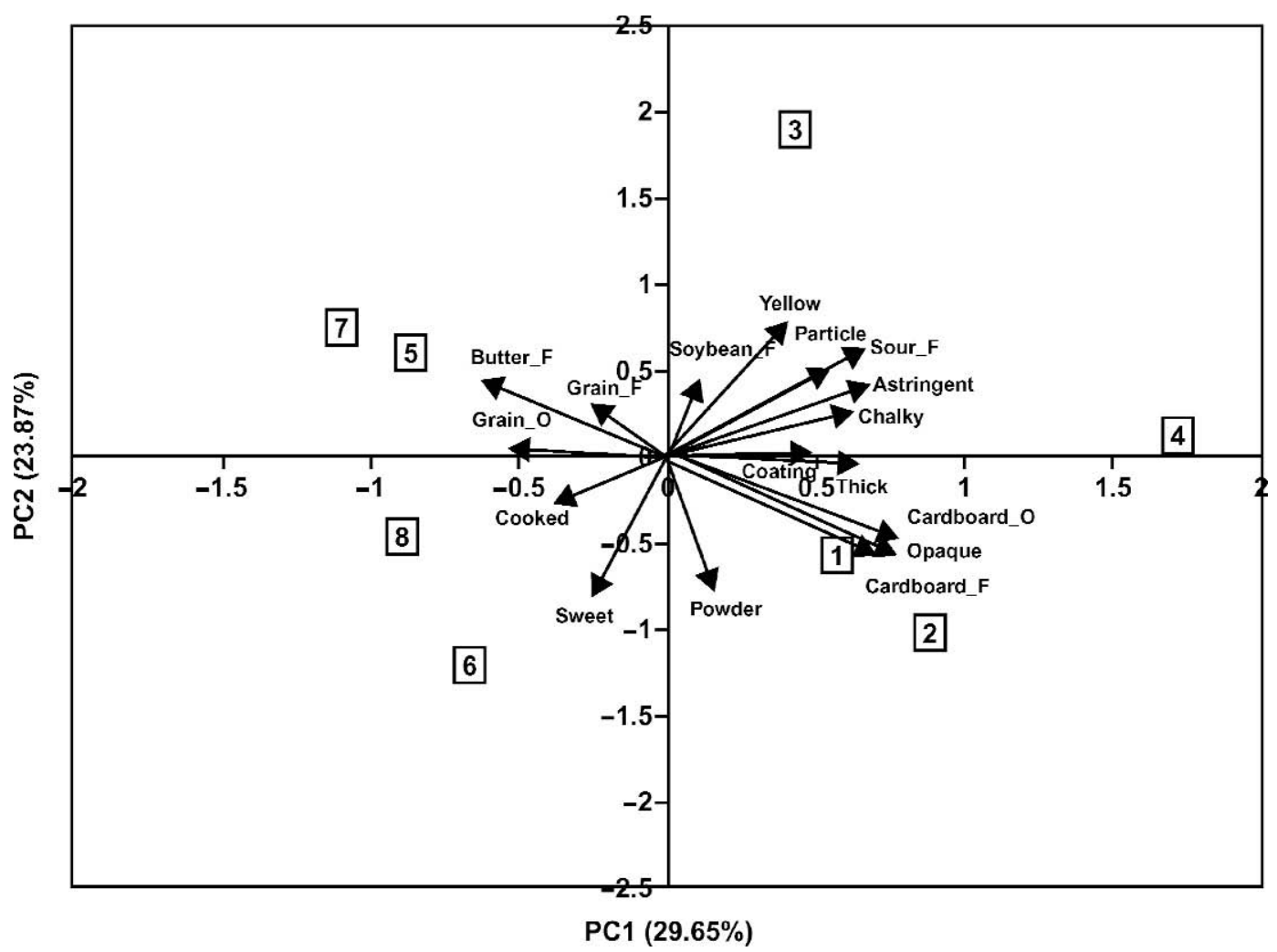

Figure 3. Principal components $(\mathrm{PC})$ plot of buttermilk samples and attributes. Sample $1=\mathrm{CBM}$ liquid; $2=\mathrm{CBM}$ powder; $3=\mathrm{WBM}$ liquid; 4 = WBM powder; $5=\mathrm{COM} 1$ liquid; 6 = COM1 powder; 7 = COM2 liquid; $8=\mathrm{COM} 2$ powder. CBM $=$ Experimental sweet cream buttermilk; WBM = experimental whey buttermilk; COM1 and COM2 = commercial sweet cream buttermilks.

and sour flavor, in addition to yellow and soybean flavor. The WBM samples had lower values of sweetness and cooked flavor. The 2 commercial liquid CBM (samples 5 and 7 ) in the upper left quadrant had more grainy flavor and aroma as well as buttery flavor, which were negatively correlated with cardboard odor and flavor and powdery. The commercial powders (samples 6 and 8 ), on the other hand, had more cooked odor and sweet flavor and less sour flavor, soybean flavor, and astringency. As mentioned above, commercial samples were related to grainy odor and flavor, cooked odor, and sweet flavor. In other research, rehydrated skim milk powder received higher intensity scores on cooked and sweet aroma than fluid skim milk (Karagül-Yüceer et al., 2004), with dimethyl sulfide and 2-acetyl thiazoline vanillin as the main compounds responsible for cooked and sweet aromas, respectively. Spill (2002) found, using principal component analysis, that butter and cooked milk odors and flavors were inversely correlated to cardboard, grain, and wet dog odors and flavors. In addition, mouthcoating, astringency, and thickness were closely related to each other. Similar results were obtained in this work with the exception of grainy odor and flavor, which in our case was correlated with butter flavor instead of cardboard flavor. It is worth noting that wet dog was not included on the list of attributes of this work.

Lee and Morr (1994) noted that the rancid off-flavors occurred not only because of lipolysis, but also because of proteolysis. Compounds generated by lipolysis included aldehydes, ketones, and alcohols (Frankel et al., 1981). Carunchia Whetstine et al. (2003) compared the flavor profiles of commercial liquid whey to milk. Liquid whey received higher intensity ratings than milk on diacetyl, sour flavor, and astringency, but sweet and cooked flavor ratings were lower. The 2 main groups of volatile compounds found in whey are aroma-active compounds and aliphatic hydrocarbons. The former compounds are aldehydes, ketones, and alcohols, which develop because of lipolysis, whereas compounds in the latter group (aliphatic hydrocarbons) do not have any aroma.

\section{CONCLUSIONS}

The 4 buttermilk types were not significantly different on several attributes, including sweetness, cooked, powdery, and grainy odors, soybean and buttery flavors, 


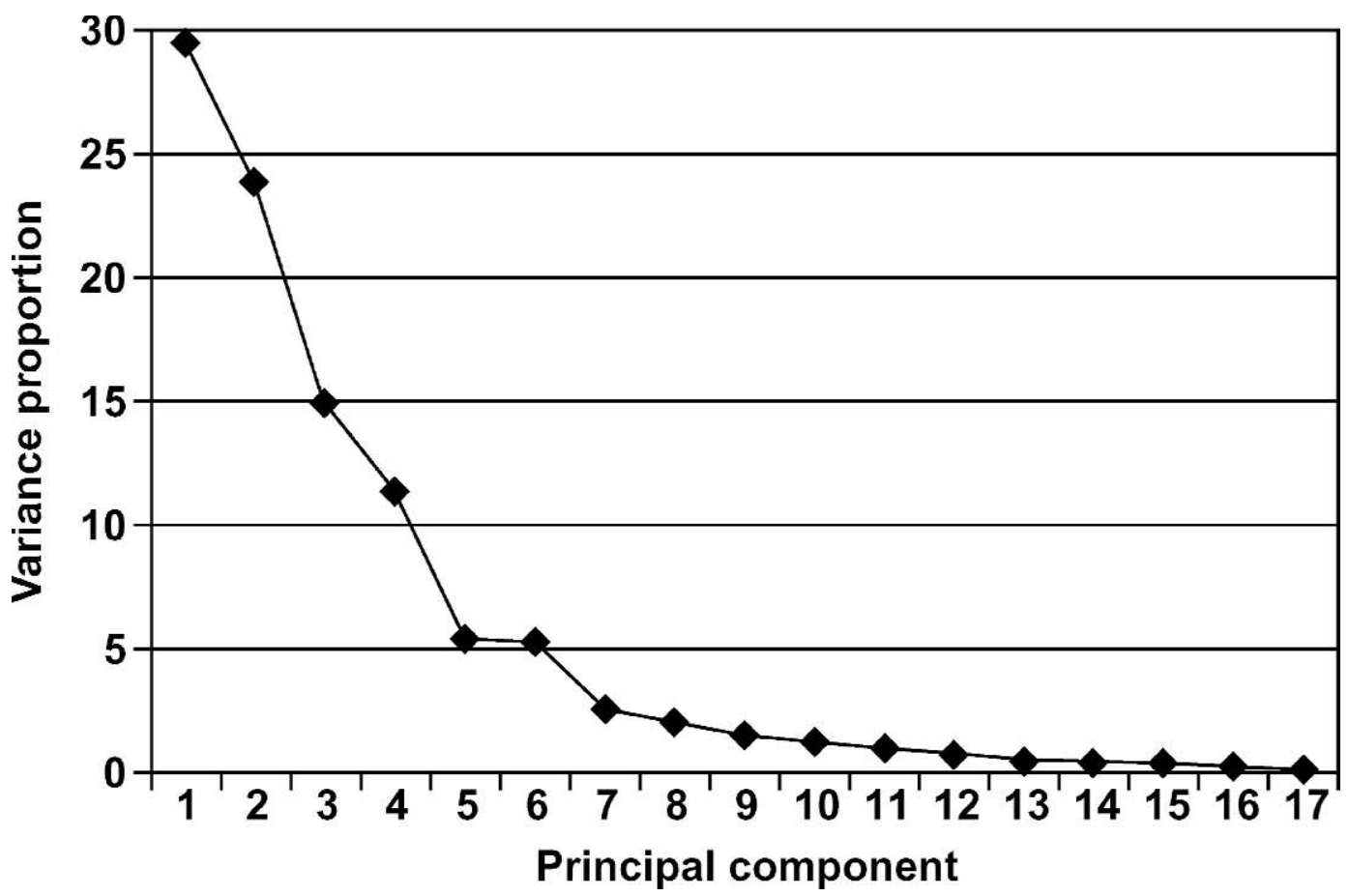

Figure 4. Scree plot of the variation accounted for by each principal component.

chalkiness, opacity, and mouthcoating. The major differences between buttermilk types were related to yellowness, which is expected given that whey buttermilk is produced from cheese whey, number of particles, cardboard odor and flavor, grain odor, sourness, and astringency. The differences in number of particles and cardboard odor and flavor between experimental and commercial samples could be due to processing differences and may warrant further investigation. However, WBM was clearly more sour and astringent than the rest of the samples. Accordingly, WBM may not have high acceptability by itself but could be successful when incorporated into food products and could add functionality to these products (Sodini et al., 2006).

The first 2 PC accounted for $53.52 \%$ of the variance in the sensory data. The first PC clearly distinguished between the production sites (commercial vs. experimental), whereas the second PC less clearly distinguished between the forms (fresh vs. powdered). Notwithstanding the differences in cardboard odor and flavor, WBM could be considered as a substitute for regular buttermilk, preferably in products where the additional sourness and astringency would not adversely affect consumer acceptability. Spill (2002) also suggested that buttermilk powder is more resistant than liquid buttermilk to oxidation, which is proven in this study in which powdered buttermilk had higher desirable attributes such as sweet and cooked flavors.
It is worth noting that this work was an exploratory one aimed at characterizing the sensory attributes of sweet cream and whey buttermilk samples from different sources and processing conditions. Additional work, including the assessment of the effect of processing variables on the sensory profile could further assist in the evaluation of whey buttermilk and shed more light on its potential applications.

\section{ACKNOWLEDGMENTS}

The funding by the Agricultural Research Initiative (CSU), Dairy Management Inc. (Rosemont, IL), California Dairy Research Foundation, and the Hilmar Cheese Company is gratefully acknowledged. The authors thank Pierre Morin, Jean-Xavier Guinard, Bernadette McInnis, Allison Pocino, Jessica Morton, and Erin Peffly for their technical assistance, and all the panelists for their dedication.

\section{REFERENCES}

Balagtas, J. V., F. M. Hutchinson, J. M. Krochta, and D. A. Sumner. 2003. Anticipating market effects of new uses for whey and evaluating returns to research and development. J. Dairy Sci. 86:1662-1672.

Bitman, J., and D. L. Wood. 1990. Changes in milk fat phospholipids during lactation. J. Dairy Sci. 73:1208-1216.

Bodyfelt, F. W., J. Tobias, and G. M. Trout. 1988. Sensory Evaluation of Butter. Pages 377-417 in The Sensory Evaluation of Dairy Products. Van Nostrand Reinhold, New York, NY. 
Carunchia Whetstine, M. E., J. D. Parker, M. A. Drake, and D. K. Larick. 2003. Determining flavor and flavor variability in commercially produced liquid Cheddar whey. J. Dairy Sci. 86:439448.

Corredig, M., and D. G. Dalgleish. 1997. Isolates from industrial buttermilk: Emulsifying properties of materials derived from the milk fat globule membrane. J. Agric. Food Chem. 45:4595-4600.

Dairy Facts. 2004. International Dairy Foods Association. Washington, DC.

Drake, M. A., Y. Karagül-Yüceer, K. R. Cadwallader, G. V. Civille, and P. S. Tong. 2003. Determination of the sensory attributes of dried milk powders and dairy ingredients. J. Sens. Stud. 18:199-216.

Farah, Z., and M. Bachman. 1981. Buttermilk flavoured with natural fruit juice - An example of a product development for developing countries. Lebensm. Wiss. Technol. 14:276-277.

Frankel, E. N., W. E. Neff, and E. Selke. 1981. Volatile thermal decomposition products of pure hydroperoxides from autooxidized and photosensitized methyl oleate, linoleate, and linolenate. Analysis of autooxidized fats by gas chromatography-mass spectrometry: VII. Lipids 16:279-285.

Gokhale, A. J., A. J. Pandya, and K. G. Upadhyay. 1999. Effect of substitution of water with sweet cream buttermilk on quality of processed cheese spread. Indian J. Dairy Sci. 52:256-261.

Hall, G. M., and O. Iglesias. 1997. Functional properties of dried milk whey. Food Sci. Technol. Int. 3:381-382.

Hammond, E. G. 1972. Oxidized flavor in milk and its simulation. J. Dairy Sci. 55:1567-1569.

Hanumantha Rao, K., and K. Atmaram. 1986. Utilization of buttermilk solids in ice cream. Scientific Session Special Number Part II. Indian Dairyman: J. Indian Dairy Sci. Assoc. 38:434-436.

Hough, G., R. H. Sánchez, G. Garbarini de Pablo, R. G. Sánchez, S. Calderón Villaplana, A. M. Gimenéz, and A. Gambaro. 2002. Consumer acceptability versus trained sensory panel scores of powdered milk shelf-life defects. J. Dairy Sci. 85:2075-2080.

Karagül-Yüceer, Y., M. A. Drake, and K. R. Cadwallader. 2004. Evaluation of the character impact odorants in skim milk powder by sensory studies on model mixtures. J. Sens. Stud. 19:1-13.

Lee, Y. B., and C. V. Morr. 1994. Lipids in food flavors: Changes in the headspace volatile compounds due to oxidation of milk fat during storage of dried dairy products. ACS Symp. Ser. No. 558. Am. Chem. Soc., Washington, DC.

Liang, B., and R. W. Hartel. 2004. Effects of milk powders in milk chocolate. J. Dairy Sci. 87:20-31.

Malin, E. L., J. J. Basch, J. Shien, B. C. Sullivan, and V. H. Holsinger. 1994. Detection of adulteration of buttermilk powder by gel electrophoresis. J. Dairy Sci. 77:2199-2206.

Mansour, A. A., M. Y. Khalifa, and N. M. Hanafy. 1994. Utilization of some dairy by-products in yoghurt manufacture. Egypt. J. Food Sci. 22:87-97.

Maubois, J. L., A. Pierre, J. Fauquant, and M. Piot. 1987. Industrial fractionation of main whey proteins. Dairy Research Laboratory, Rennes Cedex, France.
Meyers, S. A., S. L. Cuppett, and R. W. Hutkins. 1996. Lipase production by lactic acid bacteria and activity on butter oil. Pages $383-$ 389 in Food Microbiology. Vol. 13. Acad. Press, Inc., Boca Raton, FL.

Mistry, V. V., L. E. Metzger, and J. L. Maubois. 1996. Use of ultrafiltered sweet buttermilk in the manufacture of reduced fat Cheddar cheese. J. Dairy Sci. 79:1137-1145.

Muir, D. D., A. Y. Tamime, and M. Wszolek. 1999. Comparison of the sensory profiles of kefir, buttermilk, and yogurt. Int. J. Dairy Technol. 52:129-134.

O'Connell, J. E., and P. F. Fox. 2000. Heat stability of buttermilk. J. Dairy Sci. 83:1728-1732.

Parodi, P. W. 1999. Symposium: A bold new look at milk fat, conjugated linoleic acid, and other anticarcinogenic agents of bovine milk fat. J. Dairy Sci. 82:1339-1349.

Poduval, V. S., and V. V. Mistry. 1999. Manufacture of reduced fat Mozzarella cheese using ultrafiltered sweet buttermilk and homogenized cream. J. Dairy Sci. 82:1-9.

Raval, D. M., and V. V. Mistry. 1999. Application of ultrafiltered sweet buttermilk in the manufacture of reduced fat process cheese. J. Dairy Sci. 82:2334-2343.

Roesch, R. R., A. Rincon, and M. Corredig. 2004. Emulsifying properties of fractions prepared from commercial buttermilk by microfiltration. J. Dairy Sci. 87:4080-4087.

Shukla, F. C., A. Sharma, and B. Singh. 2004. Studies on the preparation of fruit beverages using whey and buttermilk. J. Food Sci. 41:102-105.

Smithers, G. W., J. Ballard, A. D. Copeland, K. J. De Silva, D. A Dionysius, G. L. Francis, C. Goddard, P. A. Grieve, G. H. McIntosh, I. R. Mitchell, R. J. Pearce, and G. O. Regester. 1996. New opportunities from the isolation and utilization of whey proteins. J. Dairy Sci. 79:1454-1459.

Sodini, I., P. Morin, A. Olabi, and R. Jimenez-Flores. 2006. Composition and functional properties of buttermilk: A comparison between sweet, sour, and whey buttermilk. J. Dairy Sci. 89:525-536.

Spill, M. 2002. Sensory and instrumental measurements of the sensory properties of powdered buttermilk. MS Thesis, Univ. Calif., Davis.

Srivastava, M. K., N. Trimurtulu, and P. P. Lohani. 1985. Utilization of by-products of dairy industries - Whey and butter-milk. Indian Dairyman: J. Indian Dairy Sci. Assoc. 37:507-509.

Tirumalesha, A., and H. M. Jayaprakasha. 1998. Effect of admixture of spray dried whey protein concentrate and butter milk powder on physico-chemical and sensory characteristics of ice cream. Indian J. Dairy Sci. 51:13-19.

Trachoo, N., and V. V. Mistry. 1998. Application of ultrafiltered sweet buttermilk and sweet buttermilk powder in the manufacture of nonfat and low fat yogurts. J. Dairy Sci. 81:3163-3171.

Wong, P. Y. Y., and D. D. Kitts. 2003a. A comparison of the buttermilk solids functional properties to nonfat dried milk, soy protein isolate, dried egg white, and egg yolk powders. J. Dairy Sci. 86:746-754.

Wong, P. Y. Y., and D. D. Kitts. 2003b. Chemistry of buttermilk solid antioxidant activity. J. Dairy Sci. 86:1541-1547. 